\title{
Formalism and Hilbert's understanding of consistency problems
}

\author{
Michael Detlefsen ${ }^{1}$
}

Received: 16 March 2019 / Accepted: 13 May 2020 / Published online: 15 June 2021

(C) The Author(s) 2021

\begin{abstract}
Formalism in the philosophy of mathematics has taken a variety of forms and has been advocated for widely divergent reasons. In Sects. 1 and 2, I briefly introduce the major formalist doctrines of the late nineteenth and early twentieth centuries. These are what I call empirico-semantic formalism (advocated by Heine), game formalism (advocated by Thomae) and instrumental formalism (advocated by Hilbert). After describing these views, I note some basic points of similarity and difference between them. In the remainder of the paper, I turn my attention to Hilbert's instrumental formalism. My primary aim there will be to develop its formalist elements more fully. These are, in the main, (i) its rejection of the axiom-centric focus of traditional model-construction approaches to consistency problems, (ii) its departure from the traditional understanding of the basic nature of proof and (iii) its distinctively descriptive or observational orientation with regard to the consistency problem for arithmetic. More specifically, I will highlight what I see as the salient points of connection between Hilbert's formalist attitude and his finitist standard for the consistency proof for arithmetic. I will also note what I see as a significant tension between Hilbert's observational approach to the consistency problem for arithmetic and his expressed hope that his solution of that problem would dispense with certain epistemological concerns regarding arithmetic once and for all.
\end{abstract}

Keywords Axiomatic method - Bernays · Conceptions of consistency · Model-construction approach to consistency - Direct approach to consistency . Formal reasoning · Formalism · Bernays · Brouwer · Dedekind · Frege $\cdot$ Heine Hilbert - Observational orientation towards consistency problems · Proof · Proof theory · Rigor · Thomae · Weyl

The editors are honored to include this beautiful essay, which is among the last papers the late Professor Detlefsen wrote, if not the very last.

\footnotetext{
$\bowtie \quad$ Michael Detlefsen mdetlef1@nd.edu

1 University of Notre Dame, Notre Dame, USA
} 
Mathematics Subject Classification 00A30 03 A05

\section{Introduction}

In Goethe's Faust, Mephistopheles offered the following cynical assessment of the role(s) played by language in theological discourse.

"Where concepts fail, a word appears at just the right time."1

In Goethe's view, genuine ideas, thoughts or judgements were in short supply in theological discourse and were commonly verbal mirages developed through the rhetorical skills of those involved.

Hilbert's collaborator, Paul Bernays, famously paraphrased Mephistopheles' remark at one point by replacing 'Wort' with 'Zeichen'- "Wo Begriffe fehlen, da stellt ein Zeichen zu rechter Zeit sich ein." (cf. [1], 16). ${ }^{2}$ He then observed that, far from being an expression of skepticism concerning the legitimacy of non-contentual uses of language in mathematics, it was actually a statement of the core "methodological principle (methodische Prinzip)" (loc. cit.) of Hilbert's formalist conception of mathematics.

On this conception, non-contentual ${ }^{3}$ methods of reasoning can and have served as valuable means of developing mathematical knowledge. By a non-contentual use of language, I mean roughly a use the cognitive significance of which is not a function of semantical contents it supposedly expresses. ${ }^{4}$ Rather, it is a use whose value is determined by the role(s) it plays in some larger symbol-manipulatory scheme of reasoning in which it participates.

An historically significant example of this type of use was the use of Cardano's law ${ }^{5}$ to solve cubic equations. Cubic equations can be given in the form of the so-called general cubic - that is, an equation of the form $x^{3}+p x+q=0$ and Cardano's law can accordingly be taken to be given by the following general formula for solving equations of this type.

$$
x=\sqrt[3]{-\frac{q}{2}+\sqrt{\left(\frac{q}{2}\right)^{2}+\left(\frac{p}{3}\right)^{3}}}+\sqrt[3]{-\frac{q}{2}-\sqrt{\left(\frac{q}{2}\right)^{2}+\left(\frac{p}{3}\right)^{3}}}
$$

There are instances where the number inside the radical sign in $\sqrt{\left(\frac{q}{2}\right)^{2}+\left(\frac{p}{3}\right)^{3}}$, is less than 0 , even though all the roots of the equation are real numbers. A stock example

\footnotetext{
1 The German was: "Denn eben wo Begriffe fehlen, Da stellt ein Wort zur rechten Zeit sich ein."

2 English translation: "Where concepts fail, a sign appears at just the right time."

3 Or what Hilbert characteristically referred to as ideal.

${ }^{4}$ Correspondingly, I will take a contentual use of an expression to be a use whose value and significance are a function of the semantical contents it expresses, or a function of the fact that it expresses such contents. The term 'contentual' is my English rendition of Hilbert's 'inhaltlich' or 'real'. His common term for 'non-contentual' was the German 'ideal.'

5 Though this law has come to be known as Cardano's law or Cardano's formula, it seems in significant part to have been the work of others.
} 
is ' $x^{3}-15 x-4=0$ ', whose roots can then be reckoned by Cardano's formula to be the real numbers $4,-2+\sqrt{3}$ and $-2-\sqrt{3}$.

Cardano's law thus provides a recognizable calculary or symbol-manipulatory method - a formula - for solving cubic equations. As such, it offers advantages of effectiveness and efficiency over alternative contentual approaches. In addition, the real or contentual solutions it identifies can be trusted to be correct. A method may therefore be useful as a means of discovering contentual truths (e.g., the equations involving the above-mentioned real roots) even though it may involve the use of an expression(s) (specifically, the radical sign in $\sqrt{\left(\frac{q}{2}\right)^{2}+\left(\frac{p}{3}\right)^{3}}$, is less than 0) whose contributions to the reasonings in which they occur are determined not by their semantical contents but by the role they play in the calculation of roots according to Cardano's law. In the example mentioned above, the calculation in question results in the eventual elimination of the ideal or non-contentual expressions (i.e., expressions which contain radical signs over negative numerals).

If this is correct, non-contentual employments of expressions can function as useful instruments in the development of mathematical knowledge (more exactly, the knowledge of contentual mathematical truths). This is the core idea of the type of position I am calling instrumental formalism. This is the type of formalist view I take Hilbert to have defended, and it will be my main preoccupation here.

Before turning to this, though, I'll briefly review the other main types of formalism of the late nineteenth and early twentieth centuries. My aim in doing so is to bring the distinctive motives of Hilbert's formalism, and particularly their mathematical origins, into clearer perspective.

\section{Two alternative forms of formalism and their motives}

The two most significant non-Hilbertian forms of formalism are what I will call (i) empirico-semantic formalism, ${ }^{6}$ and what has come to be known as (ii) game formalism.

The former centers on a view to the effect that mathematics is made up of theories whose theorems are contentual truths and whose proofs are finite deductively ordered sequences of judgements whose contents are contentual truths. What warrants calling this a formalist view is the nature of the contents of these judgements, which concern sensible signs and expressions and their sensible properties and relations.

Game formalism, on the other hand, does not take mathematics to be made up of contentual truths and proofs. It sees it instead as comprised of what are essentially "games" played according to certain "rules" of manipulation applied to semantically empty symbols and finite strings of such. The symbols and strings of symbols to which the operations are applied and which result from their application are, moreover, to be identified in terms of their outwardly sensible features.

Empirico-semantic formalism and game formalism are therefore formalist in different ways or senses. The former emphasized not the importance of non-contentual uses of language to the development of our mathematical reasoning and knowledge,

\footnotetext{
6 Also designated term formalism by various writers, e.g., Michael Resnik (cf. [29]) and Stewart Shapiro (cf. [30]).
} 
but the formal-empirical character of what it took to be the semantical contents of the truths of which mathematics was taken to be composed. The following is a well-known statement of this latter type of view by the German mathematician Heinrich Eduard Heine (1821-1881).

'I do not answer the question 'What is a number?' by defining number conceptually, say, by introducing irrationals as limits whose existence is to be presupposed. I adhere to the definition of the purely formal standpoint (rein formalen Standpunkt), in which what I call numbers are certain tangible (greifbare) signs (Zeichen) so that the existence of these numbers does not ...stand in question."

This statement suggests that Heine saw his formalist views as being motivated by the desire to secure knowledge of the existence of the presumed subject-matter of arithmetic, namely, numbers. ${ }^{7}$ The suggestion, more particularly, is that treating numbers as signs or finite sequences of signs provides such security.

Johannes Thomae (1840-1921) defended a variant of game formalism, which he described as being motivated by a concern to avoid certain difficulties to which he took at least some non-formalist views to be subject. The "difficulties" that seem to have figured most directly in his thinking were certain problems he took to confront Dedekind's logicist proposal(s).

"The formalist conception of number ... does not ask what are the numbers and what are they all about. ${ }^{8}$ Rather, it asks what one requires of the numbers in arithmetic. ${ }^{9}$ For the formalist, arithmetic is a game (Spiel) with signs (Zeichen), which are called empty. This means they have no other content (Inhalt) (in the calculating game) (im Rechenspiel) than they are assigned by their behavior with respect to certain rules of combination (rules of the game) (Spielregeln).

The formal standpoint rids us of all metaphysical difficulties (alle metaphysischen Schwierigkeiten); this is the advantage it affords us. ... It is commonly said that in the formal framework calculation (das Rechnen) is degraded (herabsinken) to a worthless (unwürdigen) game. Because of the special advantages, however, which the formal standpoint offers, I am quite happy to forego the search for the properties of the numbers along with the search for the property of worthiness (Würde)."

([32], 3 (square brackets and their contents added))

Thomae's use of the phrase "was sind und was wollen die Zahlen" seems to be a reference to the title question of Dedekind's famous essay ([10]). It may therefore be that the "metaphysical difficulties" he had in mind were certain obstacles he took Dedekind's logicist views to have faced. He may, in particular, have been thinking of what he took to be a reliance of Dedekind's analysis of the notion of number on the existence of problematically inclusive collections of thoughts. ${ }^{10}$

\footnotetext{
7 Traditionally, but also in Heine's day, the existence of a reality to serve as the subject-matter of a theory was widely regarded as a condition necessary to its justified classification as a science.

8 The German is: "Sie fragt nicht, was sind und was wollen die Zahlen." This is a clear reference to the title question of Dedekind's 1888 essay Was sind und was sollen die Zahlen?.

9 The German is: "[W]as braucht man von den Zahlen in der Arithmetik?"

10 This is a difficulty Zermelo noted regarding Dedekind's logicist proposal. Zermelo's statement post-dated Thomae's statements, though, so it could not itself plausibly be seen as having inspired them.
} 
Both Heine's empirico-semantical formalism and Thomae's game formalism thus promised advantages over non-formalist views of arithmetic. Heine promised surer knowledge of the existence of numbers, and Thomae promised avoidance of "metaphysical difficulties" (loc. cit.) concerning arithmetic.

\section{Hilbert's instrumental formalism}

The advantages - and even the broad types of advantages - that Hilbert took his formalist approach to offer were sharply different from those featured by Heine and Thomae. They had little if anything to do with securing the existence of numbers or with avoiding metaphysical difficulties, whatever, exactly, these may have been taken to be. They centered instead on the value of formal or non-contentual reasoning as a means of developing (specifically, of adding to the extent of) our mathematical knowledge.

Hilbert believed that instrumentally useful non-contentual reasoning in mathematics generally or at least often takes the form of a certain type of axiomatic reasoning - what in his later writings he referred to as "formale Axiomatik", cf. [21] (cf. pp. 1-7), or formal axiomatic reasoning. His use of the term 'formale' in this connection was intended to highlight a contrast with another type of axiomatic reasoning that he termed "inhaltliche Axiomatik", or contentual axiomatic reasoning. ${ }^{11}$

In science, Hilbert maintained, the ultimate aim is not merely, or perhaps even primarily to describe what is given in experience, but also, generally speaking, to simplify it through idealization. Such simplifications take various forms and have various benefits.

One common such benefit, Hilbert suggested, was improved effectiveness and/or efficiency in solving problems. In speaking of the use of non-semantical methods of

Footnote 10 continued

He noted in particular the following difficulty concerning the proof of Dedekind's Proposition 66, which was the core of his (i.e., Dedekind's) proposed proof of the consistency of his theory of simply infinite systems. This proposition states that there are simply infinite systems.

"The "proof" that Dedekind there offers for this principle [i.e., Proposition 66 of [10], MD] cannot be satisfactory, since it takes its departure from "the set of everything thinkable", whereas from our point of view the domain $\mathfrak{B}$ itself does not form a set."

[39], §1.13 (square brackets and their contents added)

In section 1 of [39], Zermelo called the domain of everything thinkable $\mathfrak{B}$, and he considered, and rejected, the possibility of treating it as a set (which is what he seems to have taken Dedekind to have intended). In his footnote 8 , referring to section 10 of his paper, he thus wrote "not all objects $x$ of the domain $\mathfrak{B}$ can be elements of one and the same set; that is, the domain $\mathfrak{B}$ is not itself a set.

${ }^{11}$ Hilbert and Bernays glossed these terms. In particular, they characterized contentual axiomatization as basically descriptive in character-descriptive, in particular, of what we find in experience: "[I]n contentual axiomatics, the basic relations are viewed as something to be found in our experience or intuitive conception, and thus as something contentually determined, about which the sentences of the theory are assertions." ( [21], 6).

Formal axiomatization, on the other hand, was taken to be less descriptive and more definitory and aspirational in character: "In formal axiomatization ...the basic relations are not taken as having already been determined contentually. Rather, they are determined implicitly by the axioms from the very start. And in all thinking with an axiomatic theory only those basic relations are used that are expressly formulated in the axioms." ([21], 7). 
reasoning as means of enhancing the effectiveness of our thinking, I mean their use to increase our practical capacity to solve problems that we may not have the practical capacity to solve by contentual means alone.

The use of the sign ' $\sqrt{-1}$ ' in applications of Cardano's Law to aid in root extractions for cubic equations is an example of this type of usage. Formulaic application of Cardano's Law practically aids these extractions by structuring or guiding them in the ways that use of formulas customarily guides the solution of equations. Application of Cardano's Law presumes that the cubic equation whose resolution is in question is given in so-called reduced form (i.e., in the form $x^{3}+p x+q$, where $p$ and $q$ are reals). Cardano's Law does not aid one in the task of putting an equation not in reduced form into reduced form. It does, however, allow one to proceed in a formulaically structured way once a cubic in reduced form has been obtained. It is in this way that it aids development of knowledge of the roots of cubic equations.

A similar capacity for extending knowledge is provided by the use of ideal elements in projective geometry. There the introduction of so-called points "at infinity" gives rise to the familiar point-line duality that results from the introduction of points at infinity to serve as points of intersection of pairs of parallel lines. This duality allows us to obtain, from a given theorem concerning points and lines, a second such theorem which is its dual. The procedure to be followed in this process is moreover a routine process of substitution. ${ }^{12}$ Here is a representative statement of this basic idea from an early twentieth century textbook.

"From any known theorem we are ... able to write down a reciprocal theorem whose truth we can at once assert; and we have thus a useful and valuable method of extending our knowledge of geometrical properties."

Both of the above-mentioned applications of ideal elements/methods thus appear to have utility as means of extending knowledge (as distinct from developing it $a b$ initio). I'll close this brief survey of basic examples of the use of ideal elements to instrumentally aid development of knowledge by considering a different type of case also noted by Hilbert. This was their use as means of simplifying whole practices of reasoning in order to make them more useful to us.

In this connection, he considered in particular what we might call the logical part(s) of our reasoning practices. It was in fact proper management of our logical reasoning that was Hilbert's main reason for advocating the preservation of what he termed ideal propositions $^{14}$ as means of mathematical reasoning. They did this by allowing the use

\footnotetext{
12 Similar processes of dualization exist for other ideal elements too (e.g., lines at infinity).

13 For similar statements see [8], 25 and [26], 4.

${ }^{14}$ Hilbert described his distinction between real and ideal sentences (which he also, somewhat misleadingly, referred to as propositions) as follows: Real sentences/propositions are used to communicate a semantical content, and the role they play in mathematical reasoning is determined by this content and the attitudes taken towards it. Ideal sentences/propositions are different. Their contribution to mathematical reasoning is determined not by any content they're intended to express but by the role(s) they're intended to play in one or another specified derivational apparatus. For expressions of these ideas, see, among other places, [18], 160 and [19], 7-9.

Both the real/ideal terminology and the ideas behind it are older, of course, going back to writers of the modern era (cf. [11], Bk. III, 175; [27], 412-413).
} 
of rules of manipulating formulae which, at the level of syntax, were parallel to the familiar laws of classical, Aristotelian logic.

Hilbert saw this parallel as somehow enhancing the value of classically conducted formal reasoning (i.e., formal reasoning whose syntactic manipulations follow the forms and inferences of classical, Aristotelian logical reasoning). ${ }^{15}$

"In the domain of finitary propositions, in which we should, after all, remain, the logical relations that prevail are very imperspicuous, and this lack of perspicuity mounts unbearably if 'all' and 'there exists' occur combined or appear in nested propositions. In any case, those logical laws that man has always used since he began to think, the very ones that Aristotle taught, do not hold. Now one could attempt to determine the logical laws that are valid for the domain of finitary propositions; but this would not help us, since we just do not want to renounce the use of the simple laws of Aristotelian logic, and no one, though he speak with the tongues of angels, will keep people from negating arbitrary assertions, forming partial judgments, or using the principle of excluded middle."

Hilbert thus allowed that it might be in principle possible to conduct our logical reasoning according to a non-classical (specifically, a finitist) plan when proving real or contentual propositions (and/or formulae which under preferred interpretation express them). This notwithstanding, he emphasized that such conduct would not, from a practical vantage, be desirable. This in Hilbert's view was because, at least as a matter of practical disposition, our logical reasoning follows the forms and inferential patterns of classical logic.

Because of this tendency or disposition, Hilbert believed, mathematicians are, at least under certain circumstances, rationally entitled to conduct their logical reasoning in a classical manner. This included situations in which the conclusions of such reasoning may be interpretable as real or contentual propositions.

Hilbert identified two conditions as proper constraints on the use of such noncontentual reasoning. The more prominent of these was his well-known consistency requirement, whose function he described as follows:

"[T]here is a condition, a single but absolutely necessary one, to which the use of the method of ideal elements is connected, and that is the proof of consistency (Nachweis der Widerspruchsfreiheit); for, extension by the addition of ideals is legitimate only if no contradiction is thereby brought about in the older, narrower domain, that is, if the relations that result for the old objects whenever the ideal objects are eliminated are valid in the old domain."

$\left([18], 179\right.$, emphasis in text $\left.{ }^{16}\right)$

\footnotetext{
15 Perhaps by increasing its effectiveness and/or efficiency, though Hilbert seems not to have said this in so many words in any explicit statement he made concerning the value of following the classical patterns in logical reasoning.

16 The reader should note that the consistency requirement Hilbert states here is not simply that the body of ideal reasoning $I$ whose consistency is in question should be consistent. Rather, it is that it should be consistent with the accepted reasoning of that older, narrower domain $R$ it is presumed to extend. Taking this into account, Hilbert's condition is naturally read as follows: For every sentence $S$ in the language of $R$ (which may be presumed to be a sub-language of the language of $I$ ), if $S$ is provable in $R, \neg S$ is not provable in the extended theory $I$.
} 
The less prominent constraint was a fruitfulness condition, which was intended to ensure that ideal methods that are added to a domain of real thinking in order to enhance its effectiveness and/or efficiency in fact have this effect.

"[I]f justifying (Berechtigung) a procedure (Maßnahme) means anything more than proving its consistency, it can only mean determining whether the procedure is successful in fulfilling its purpose (von einem entsprechenden Erfolg begleitet ist). Indeed, success (Erfolg) is necessary; here, too, it is the highest tribunal (die höchste Instanz), to which everyone submits."

In what remains here, I want to explore Hilbert's understanding of consistency problems and the conditions of their proper resolution. These involved much more than the above-quoted statement of consistency problems might lead one to believe.

The usual conception of consistency for an axiomatic theory in Hibert's day was that it consisted essentially in the existence of a model for the axioms of that theory. Correspondingly, the usual view of what was required for the proper resolution of a consistency problem was that it consisted essentially in proving the existence of such a model-more specifically, it consisted in the identification or construction of such a model. Hilbert disagreed both with this conception of consistency, and with the associated view of what is required for the proper resolution of a consistency problem. It is to these views that I now turn.

\section{Hilbert on consistency problems and their resolution}

\subsection{Concerns regarding the axiom-centricity of the traditional approach to consistency problems}

A key feature of the traditional model-construction approach to consistency problems, and one which sharply separates it from Hilbert's approach, is what I will refer to as its axiom-centricity. By this, I mean (i) the relatively heavy emphasis the model-construction approach to consistency problems has traditionally placed on the axiomatic elements (i.e., the axioms) of a body of axiomatic reasoning, and (ii) the correspondingly slight attention they have given to their non-axiomatic elements (i.e., the methods used in reasoning with the axiomatic elements).

In describing the model-construction approach to consistency problems (and their resolution) as axiom-centric, I do not mean to suggest that those who have adopted this type of approach have denied or overlooked the possibility that bodies of reasoning with axioms may be inconsistent even though the axioms on which they center should not be. They have not. This notwithstanding, however, the traditional approach to consistency problems has generally not treated the non-axiomatic elements of bodies of axiomatic reasoning with the seriousness and care with which Hilbert treated them or, I would say, with the seriousness and care they deserve. ${ }^{17}$

\footnotetext{
17 By 'the non-axiomatic elements' of a body of axiomatic reasoning, I mean the elements of it that are not proper axioms (as distinct from logical axioms, say). Among these, I include the principles and rules of logical inference by whose application reasoning with a group of axioms has traditionally been taken to proceed.
} 
Why do I say this? In large part because of two differences between Hilbert's approach to consistency problems and the traditional model-construction approach to them. One of these concerns the seriousness of the perceived threat to consistency posed by the non-axiomatic elements of a body of axiomatic reasoning. The other has to do with the means by which we may properly (or at least most properly) come to know what the non-axiomatic elements of a body of axiomatic reasoning are. ${ }^{18}$

À propos the former, Hilbert regarded the threat to consistency posed by the nonaxiomatic elements of a body of axiomatic reasoning as serious. Given his awareness of Brouwer's views concerning the capacity of the principles of classical logic to sustain paradox, it is perhaps only natural that he (i.e., Hilbert) should have felt a need to pay more careful attention to the role played by choice of logical principles (which are among the non-axiomatic elements of a scheme of axiomatic reasoning) in the emergence of inconsistencies.

Weyl highlighted this aspect of Hilbert's approach to consistency problems as one of its more distinctive and enduring virtues.

"[W]hatever the ultimate value of Hilbert's program, his bold enterprise can claim one merit: it has disclosed to us the highly complicated and ticklish logical structure of mathematics, its maze of back-connections, which result in circles of which it cannot be gathered at a first glance whether they might not lead to blatant contradictions."

What Weyl described here as Hilbert's "bold enterprise" was his proposed prooftheoretical approach to the consistency problem for arithmetic, a pivotal feature of which was that it

"[R]equire[d] that we make the propositions, rather than the things of which they speak, the object of our investigation, and that, as a preliminary, we fully analyze the logical mechanism of deduction."

([36], 637, square brackets and their contents added)

Commenting further, Weyl characterized the axiom-centricity of the modelconstruction approach to consistency as "a wonderful trick to avoid that sort of logical investigations (sic)" (loc. cit.). ${ }^{20}$

For purposes of judging the consistency of a body of axiomatic reasoning, then, Hilbert attached a weight to its non-axiomatic elements (i.e., the elements of the logical or deductive apparatus) that was comparable to the weight he assigned to its axiomatic elements. Weyl noted this as a key difference between Hilbert's proposed syntactical or proof-theoretic approach to consistency problems (specifically, to the consistency problem for arithmetic) and the traditional axiom-centric model-construction approach to them. Both points seem right to me.

\footnotetext{
18 There was an element of non-axiom-centricity even in Hilbert's early characterizations of consistency problems. Cf. the statement from [16], 264 quoted above, where he defines consistency in terms of deducibility rather than satisfiability.

19 The original German version of [37] was first published in 1927 as [34]. The passage just quoted was not present in its entirety in the earlier version. A significant part of it was, though, and that part may be found on pp. 48-49 of [34].

20 This remark was part of a larger comment on independence questions. There is no distortion, though, in offering it as a comment on consistency problems. Consistency problems form a subcategory of independence problems, and Weyl saw them this way (cf. [37], 20).
} 


\subsection{Traditional and formalist reasoning}

A second difference between the traditional approach and Hilbert's approach to consistency problems concerns Hilbert's rejection of the traditional contentualist conception of reasoning and proof and his adoption of a non-traditional formalist conception of it.

What I'm referring to here as the traditional conception of reasoning and proof centered on the idea that an argument is a finite, logically ordered sequence of judgments. ${ }^{21}$ In describing the constituent judgements of a proof as being "logically ordered", I mean their arrangement according to an order of perceived relationships of logical consequence between their propositional contents (or combinations of their propositional contents).

The following is an influential statement of this type of view by Thomas Reid.

"Reasoning is the process by which we pass from one judgment to another, which is the consequence of it. Accordingly our judgments are distinguished into intuitive, which are not grounded upon any preceding judgment, and discursive, which are deduced from some preceding judgment by reasoning.

In all reasoning, therefore, there must be a proposition inferred, and one or more from which it is inferred. And this power of inferring, or drawing a conclusion, is only another name for reasoning; the proposition inferred being called the conclusion, and the proposition or propositions from which it is inferred, the premises."

([28], Essay VII, Of Reasoning, 475²2)

Hilbert rejected this as an inaccurate view of the general nature of reasoning and proof in mathematics. He allowed that it nearly enough captures the character of some mathematical proofs-namely, those that Hilbert, following tradition, termed real or contentual proofs. This notwithstanding, however, he did not see it as an accurate description of the nature of those proofs he commonly referred to as ideal or noncontentual.

Hilbert's rejection of the traditional conception of reasoning and proof was a signal feature of his consistency program. Weyl noted this in the following remark.

"Before Hilbert constructed his proof theory everyone thought of mathematics as a system of contentual (inhaltliche), meaningful (sinnerfüllte), and evident (einsichtige) truths; this point of view was the common platform of all discussions. ... Brouwer, like everyone else, required of mathematics that its theorems be (in Hilbert's terminology) "real propositions", meaningful truths."

\footnotetext{
21 The term "judgment" here is used in its traditional sense in which it signifies the taking of an attitude of affirmation towards a genuine proposition (sometimes referred to as the propositional content of the judgment).

22 The classical statement of this view was that given in the Prior Analytics, Book I. An influential statement from the modern era was [24], Bk IV, ch. xvii, §4. Examples from the nineteenth and early twentieth centuries include [3], §22 and [23], 384.
} 
$\left([35], 22^{23,24}\right)$

In Hilbert's view, proof was not properly restrictable to traditionally conceived contentual proofs. The manifest use and usefulness of non-contentual "algebraic calculation" ("algebraic calculation with letters (algebraischen Buchstabenrechnung)" ( [18], 174-175)) as an instrument of mathematical reasoning made this clear. In keeping with this conviction, Hilbert opted for a conception of proof that left room for a type of proof or proof-like enterprise that did not consist in deductive reasoning with judgements having propositional contents. Rather, it consisted in the application of formal operations to formal objects according to certain specified schemes of applying such operations.

Hilbert's promotion of the likes of algebraic calculation as legitimate procedures of reasoning or proof was strongly opposed by certain foundational writers of his day. Among these, Brouwer, with his "first act of intuitionism", was perhaps the most conspicuous. $^{25}$ As the following remark of Frege's clearly shows, though, intuitionists were not the only ones to vigorously defend the traditional contentualist conception of the nature of proof.

"[A]n inference (Schluß) does not consist of signs. We can only say that in the transition from one group of signs to a new group of signs, it may look now and then as though we are presented with an inference. An inference simply does not belong to the realm of signs (Gebiete der Zeichen); rather, it is the pronouncement of a judgment (Urteilsfällung) made in accordance with logical laws on the basis of previously passed judgments. Each of the premises is a determinate thought recognized as true; and in the conclusion, too, a determinate thought is recognized as true ..."

Hilbert's algebraic calculation with letters, and other forms of formalist reasoning, were not intended to be reasoning of the type described by Frege. This notwithstanding, there was a type of contentual reasoning with which it might be easily enough be confused, and Hilbert made some effort to distinguish the two. This was a type of contentualist reasoning which concerns symbols and their formal properties and relationships. Hilbert took judgements regarding such contents to be characteristic of "intuitive number theory" (der anschaulichen Zahlentheorie) (op. cit., 174). In this domain of judgement and reasoning, symbols and formulae were used to "express" formal contents (e.g., "letters express (bedeuten) numerals, and the fact that two signs are identical is expressed by an equation", loc. cit.). These contents could then become the contents of genuine judgements which could in turn be related to one another by discerned relationships of logical consequence-just as in the traditional contentualist conception of reasoning/proof.

\footnotetext{
${ }^{23}$ For a similar statement, see [36], 640. See also [4], 336; [5], 490-492 and [7], 2-5 for related ideas and arguments.

24 This statement is largely though not entirely accurate. Specifically, it does not do full justice to the non-traditional, formal criteria of proof offered in pre-Hilbertian times by such writers as Pasch and Peano. Cf. [38], 51.

25 Brouwer stated of the first act of Intuitionism that it "completely separates mathematics from mathematical language, in particular from the phenomena of language which are described by theoretical logic, and recognizes that intuitionist mathematics is an essentially languageless activity of the mind ...", [6], $140-141$
} 
In algebraic calculation with letters, on the other hand, formulae did not serve to express propositional contents of any type, whether contents concerning the formal properties of formal objects or some other type of content. Similarly, reasoning using these formulae was not taken to be constituted by logical inference based on judgements of relationships of logical consequence between propositional contents concerning formal objects and their formal properties. In this type of genuinely formalist reasoning Hilbert had in mind, formulae are not treated as expressing contents of any type. Rather, they are treated as perceivable objects that have certain discernible features in terms of which the rules of operation of an algebraic-calculary derivational scheme are stated. ${ }^{26}$

Hilbert took this type of algebraic-calculary reasoning to play an important part both in scientific and in everyday thinking.

"In our theoretical sciences we are accustomed to the use of formal thought processes (formaler Denkprozesse) and abstract methods ... [But] already in everyday life (täglichen Leben) one uses methods and concept-constructions (Begriffsbildungen) which require a high degree of abstraction and which only become plain through unconscious application of the axiomatic method (nur durch unbewußte Anwendung der axiomatischen Methoden verständlich sind). Examples include the general process of negation and, especially, the concept of infinity."

In his view, the use of formal thought-processes was thus partially constitutive of (some of) our mathematical proofs or provings. That Hilbert took this view was, as Weyl noted, part of the reason why his approach to consistency proofs took symbols, formulae and certain of their finite combinations as their objects. His aim was to establish the consistency of our mathematical thinking, and our mathematical thinking was in his view partly constituted by algebraic-calculary derivations. He thus required a method of proving consistency that applied to reasonings that were at least partly constituted by the application of algebraic-calculary operations.

\subsection{Hilbert on consistency problems and the observation of reasoning}

Hilbert thus embraced a view of consistency problems and their resolution that was based on a proposed correction of what he saw as two points of unwarranted narrowness in the traditional model-existence conception of consistency and its accompanying model-construction conception of consistency proofs. The first of these was what Hilbert saw as its unjustifiedly narrow focus on the (proper) axioms (as distinct from the non-axiomatic elements) of a body of axiomatic reasoning, or what I've thus far generally referred to as the axiom-centricity of the traditional model-construction approach to the solution of consistency problems.

The second was its adoption of what Hilbert judged to be an unwarrantedly narrow traditional "contentualist" conception of proof, a conception according to which a

\footnotetext{
26 As Hilbert put it, they are treated as "concrete objects that in their turn are considered by perceptual intuition, and the derivation (Ableitung) of one formula from another in accordance with certain rules takes the place of the number theoretic proof based on content" (op. cit., 175).
} 
proof must be a finite sequence of judgements ordered according to perceived relations of logical consequence among their propositional contents.

I'd now like to consider a final and seemingly little noticed point concerning Hilbert's approach to consistency problems. It concerns what I will call its descriptive or observational orientation as regards the identification of the targets of consistency investigations.

As noted above, the consistency problem with which Hilbert was most concerned was the consistency problem for the arithmetic of the real numbers. This latter phrase, though — "the arithmetic of the real numbers"- was less than fully clear, and its lack of clarity was due in part to the indefiniteness during most of Hilbert's foundational period of what the non-axiomatic elements of the arithmetic of the real numbers were or ought most reasonably to have been taken to be.

Hilbert's announcement of his consistency problem in the Paris lecture was written decades before there was a settled formal specification of the non-axiomatic parts of mathematical reasoning. It is therefore not surprising that though Hilbert was relatively confident of what the axioms of the arithmetic of the real numbers might reasonably be taken to be (cf. [17]), he doesn't seem to have had the same confidence concerning what the non-axiomatic elements of reasoning with these axioms are.

Surprisingly perhaps, Hilbert indicated an important role for observation in determining these elements. There are indications in fact that he saw such observation as requisite for the attainment of his preferred form of consistency proof for arithmetichis so-called "direct" proof of consistency.

"I am convinced that it must be possible to find a direct proof (einen direkten Beweis) for the consistency (Widerspruchslosigkeit) of the arithmetical axioms by a precise working through (genau durcharbeitet) ... of the known methods of reasoning (die bekannten Schlußmethoden) in the theory of irrational numbers."

What I am describing as observation of our reasoning with the axioms of arithmetic is what I take Hilbert to have had in mind when he identified "a precise working through of the known methods of reasoning in the theory of irrational numbers" (loc. cit.) as the means by which the non-axiomatic elements of our reasoning with the axioms of arithmetic were to be identified.

To avoid misunderstanding, let me note two related points before proceeding further. The first is that in the remark just quoted, Hilbert describes his consistency problem as "the consistency of the arithmetical axioms" (loc. cit.). In falling into this way of speaking, he failed to distinguish as clearly as he might the consistency problem for a set of axioms per se from the consistency of a body of reasoning with those axioms.

The second is that the above remark was one of two statements of the consistency problem for arithmetic that Hilbert gave in the Paris address. The other put less emphasis on the importance of observing our methods of reasoning and had a more prescriptive flavor to it.

"Above all I wish to designate (bezeichnen) the following as the most important among the numerous questions which can be asked with regard to the axioms: To prove that they are not contradictory, that is, that a finite number of logical inferences (logischen Schlüssen) based upon them can never lead to contradictory results." 
Here it seems natural to take what Hilbert referred to as "logical inferences" as inferences that are logical in a normative sense - that is, in a sense of satisfying certain norms or ideals of rational inference in our reasoning.

Hilbert's early descriptions of his consistency program, though suggestive, were therefore not as clear as we might wish them to have been concerning the role of observation in fixing the object of his envisioned consistency proof for arithmetic. Certain of his later descriptions seem in this respect to have been clearer.

"The fundamental idea (Grundidee) of my proof theory (Beweistheorie) is none other than to describe (beschreiben) the activity of our understanding (die Tätigkeit unseres Verstandes), to make a protocol of the rules according to which our thinking actually proceeds (unser Denken tatsächlich verfährt). Thinking (Das Denken), it so happens, parallels (geschieht eben parallel) speaking and writing: we form statements and place them one behind another. If any totality of observations (Beobachtungen) and phenomena (Erscheinungen) deserves to be made the object of serious and thorough investigation (ernsten und grundlichen Forschung), it is this one ..."

Hilbert therefore seems to have viewed his envisioned proof for the consistency of arithmetic as most fundamentally intended to be a proof of the consistency of our actual reasoning - that is, the reasoning of the dominant mathematical community of his day - with the axioms of arithmetic. It was not, or at least was not simply, to be a proof of the consistency of the axioms of arithmetic themselves. Nor was it to be a proof of the consistency of some presumedly ideally logical body of reasoning with these axioms.

This should not be taken to suggest that Hilbert shunned all idealization in carrying out his consistency program for arithmetic. His view, briefly, was that the direct target of a consistency proof of arithmetic was a simplifying or systematizing idealization of our actual reasoning with the axioms of arithmetic that permitted the application of mathematical methods of thinking in addressing its consistency. By directly addressing the consistency problem for this idealization, we ultimately provide for the solution of the consistency problem for our actual arithmetical thinking. His consistency program for arithmetic seems therefore to have been intended to proceed in the following three stages: (i) observation of our actual reasoning with the axioms of arithmetic in order to identify its methods, (ii) codification and systematization of these methods and (iii) development of a proof-theoretic proof of the consistency of this systematizing idealization of our actual reasoning.

\section{Conclusion}

My primary aim in this paper has been to expose and to explain what I take to be the principal formalist elements of Hilbert's instrumentalistic form of formalism. Here I focused particularly on the three following distinctive and interrelated features of his formalist program for arithmetic: 
(i) His rejection of the axiom-centric focus of traditional model-construction approaches to consistency problems, and his emphasis on the important role that the non-axiomatic elements of axiomatic reasoning play in determining the consistency of a body of axiomatic reasoning,

(ii) His rejection of the traditional contentualist understanding of the basic nature of proof in favor of an expanded conception which makes room for the use of formalist methods of in proof, and

(iii) His distinctively descriptive or observational orientation with respect to the consistency problem for arithmetic.

The first of these stemmed mainly from the important role Hilbert believed logical methods of (or what I have here more broadly termed "non-axiomatic" methods of) reasoning to have traditionally played in mathematical reasoning. Because of their prominence as means of mathematical reasoning, the possibility that they should introduce inconsistencies into our thinking ought to be taken seriously. Hilbert's prooftheoretic approach to the consistency problem for arithmetic-in stark contrast to traditional model-construction approaches to consistency problems-made systematic provision for doing this.

The second seems to have been due primarily to the fact that Hilbert saw formalist reasoning (e.g., Hilbert's so-called method of "algebraic calculation with letters" (loc. cit.)) as having had a well-attested-to place in the conduct of proof in the history of mathematics. The view that formalist reasoning plays an important role in the conduct of mathematical proof is what I have called conductive formalism. ${ }^{27}$

Hilbert, in my view, was a conductive formalist. Like various other formalists, too, ${ }^{28}$ he believed that formalization also has an important role to play in representing mathematical proof as part of readying it for mathematical study. Because of this, I also count Hilbert as a representational formalist.

The view that formalization plays an important role in the preparation of mathematics for certain metamathematical investigations of mathematical proof is what I have called representational formalism.

The third of the above-listed rudiments of Hilbert's formalism primarily reflects, in my view, the importance to him of his commitment to (ii). Since formalist reasoning plays an important part in mathematical reasoning, it is only natural and reasonable that we should pay commensurate attention to the careful observation and description of that role when investigating consistency problems.

But though the account given here may go some way towards deepening our understanding of Hilbert's formalism and the ways in which it figured in his consistency program for arithmetic, it does not quiet certain questions concerning it.

Among these, I will briefly mention two. The first concerns a description of an intended effect of Hilbert's program for arithmetic that Hilbert (and his student Bernays) promoted. This is that it should in the end have the effect of disposing of foundational questions - and specifically, of consistency problems_-once and for

\footnotetext{
27 Among formalists, Curry emphasized its conductive side. See [9], 175-176; [12] for more on this.

28 Prominent among whom was Gentzen. Gentzen seems not to have been a conductive formalist but only a representational formalist. Cf. [12].
} 
all. Speaking of his proof-theoretic approach to consistency problems in 1930, Hilbert said this:

"With this new grounding of mathematics, which one can appropriately call a proof theory (eine Beweistheorie), I believe I have provided for the final disposition of the problems of the foundations of mathematics (die Grundlagenfragen der Mathematik als solche endgültig aus der Welt zu schaffen) by transforming every mathematical proposition into a concretely exhibitable and rigorously derivable formula, thereby transferring the whole complex of questions into the domain of pure mathematics (dadurch den ganzen Fragenkomplex in die Domäne der reinen Mathematik versetze)."

It is difficult for me to see a sound basis for such a view. Surely there is no guarantee that our reasoning concerning irrational numbers, or our view of what that reasoning consists in, will not change with time. If it were to change, though, would we not for that reason stand in need of a new proof of the consistency of that reasoning? It seems to me that we would, and the fact (if it were a fact) that we had proven the consistency for an older observation of our reasoning with irrational numbers would not change that. $^{29}$

A second point concerns Hilbert's apparent view that he requires a proof theoretic proof of consistency only for arithmetic and that model-construction proofs should suffice everywhere else, or at least for every other theory that can be interpreted in arithmetic.

Such a view would seem to rely on an assumption to the effect that it is only with respect to our reasoning concerning the irrationals that careful observation is requisite for a proper reckoning of what it is that is to be proved consistent.

I don't see why this should be so. So far as I can see, the observation of reasoning would seem to matter just as much (or just as little) for the proper identification of what belongs to a non-arithmetical domain of thinking as for what belongs to an arithmetical domain. If this is so, though, what could justify the asymmetry of scrutiny or observation that Hilbert seems to apply to the consistency problem for arithmetic vs. the consistency problems for various other theories whose axioms he believes to be consistent relative to the consistency of the axioms of arithmetic? Is axiom-centricity less objectionable in non-arithmetic domains than in the domain of arithmetic? If so, for what reason(s)?

Funding Open access funding provided by University of Helsinki including Helsinki University Central Hospital.

Open Access This article is licensed under a Creative Commons Attribution 4.0 International License, which permits use, sharing, adaptation, distribution and reproduction in any medium or format, as long as you give appropriate credit to the original author(s) and the source, provide a link to the Creative Commons licence, and indicate if changes were made. The images or other third party material in this article are included in the article's Creative Commons licence, unless indicated otherwise in a credit line to the material. If material is not included in the article's Creative Commons licence and your intended use is not permitted

\footnotetext{
29 Weyl suggested such a view too: "Should a new and evidently stringent method of logical inference be discovered and ...the set of rules of the game be augmented, one would have to be prepared to see a consistency proof conducted by the direct method become obsolete" ( [37], 23) and in need of replacement.
} 
by statutory regulation or exceeds the permitted use, you will need to obtain permission directly from the copyright holder. To view a copy of this licence, visit http://creativecommons.org/licenses/by/4.0/.

\section{References}

1. Bernays, P.: Über Hilbert's Gedanken zur Grundlegung der Arithmetik. Jahresberichte der deutsche Mathematiker-Verienigung 30, 10-19 (1922). English trans. in [26]

2. Bolzano, B.: The Mathematical Works of Bernard Bolzano, trans. and ed. by Steve Russ. Oxford University Press, Oxford (2004)

3. Bolzano, B.: Beiträge zu einer begründeteren Darstellung der Mathematik, Caspar Widtmann, Prague, 1810. English trans. in [2]

4. Brouwer, L.E.J.: Über die Bedeutung des Satzes vom ausgescholessenen Dritten in der Mathematik, insbesondere in der Funktiontheorie. Journal für die reine und angewandte Mathematik 154, 1-7 (1923) English translation in [15], 334-345. Page references are to this translation

5. Brouwer, L.E.J.: Intuitionistische Betrachtungen über den Formalismus, Koninklijke Akademie van wetenschappen de Amsterdam. Proc. Sect. Sci. 31, 324-329 (1928) English translation with introduction in [Hei67], 490-492. Page references are to this translation

6. Brouwer, L.E.J.: Historical background, principles and methods of intuitionism. South Afr. J. Sci. 49, 139-146 (1952)

7. Brouwer, L.E.J.: Brouwer's Cambridge Lectures on Intuitionism. In: D. van Dalen (ed.), Cambridge University Press, Cambridge (1981)

8. Coxeter, H.: Introduction to Geometry, 2nd edn. Wiley, New York (1969)

9. Curry, H.: Mathematics, syntactics and logic. Mind 62, 172-183 (1953)

10. Dedekind, R.: Was sind und was sollen die Zahlen?, F. Vieweg, Braunschweig, 1887. Reprinted in Dedekind R. (1932). Page references are to this reprinting

11. Descartes, R.: La Géométrie, 1637. First published as an appendix to the Discourse on Method (1637). Page references are to the English translation by D. Smith and L. Latham, Dover, New York (1954)

12. Detlefsen, M.: Gentzen's Anti-formalist Ideas. In: Rathjen, M., Kahle, R. (eds.) Gentzen's Centenary: The Quest for Consistency, pp. 25-44. Springer (2015)

13. Frege, G.: Über die Grundlagen der Geometrie. Jahresbericht der Deutschen MathematikerVereinigung 15, 293-309, 377-403, 423-430 (1906). English translation in [14] (1906)

14. Frege, G.: Gottlob Frege: On the Foundations of Geometry and Formal Theories of Arithmetic, trans. and ed., with an introduction, by Eike-Henner W. Kluge, Yale University Press, New Haven, Conn. (1971)

15. Heine, H.E.: Die Elemente der Functionenlehre. Journal für die reine und angewandte Mathematik 74, $172-188$ (1872)

16. Hilbert, D.: Mathematische Probleme. Göttinger Nachrichten 253-297 (1900)

17. Hilbert, D.: Über den Zahlbegriff. Jahresbericht der Deutschen Mathematiker-Vereinigung 8, 180-194 (1900)

18. Hilbert, D.: Über das Unendliche. Mathematische Annalen 95, 161-190 (1926)

19. Hilbert, D.: Die Grundlagen der Mathematik. Abhandlungen aus dem mathematischen Seminar der Hamburgischen Universität 6, 65-85 (1928). Reprinted in Hamburger Einzelschriften 5, pp. 1-21. Teubner, Leipzig, 1928. Page references are to this reprinting (1928)

20. Hilbert, D.: Probleme der Grundlegung der Mathematik. Atti del Congresso internazionale dei matematici (Bologna, 1929), vol. 1, 135-141; reprinted, with emendations and additions, in Mathematische Annalen 102 (1929),1-9

21. Hilbert, D., Bernays, P.: Grundlagen der Mathematik, vol. I, Springer Verlag, Berlin, 1934. Page references are to [23], the second edition of this text (1934)

22. Hilbert, D., Bernays, P.: Grundlagen der Mathematik, vol. I, 2nd edn. Springer Verlag, Berlin (1968)

23. Klein, F.: Elementarmathematik vom höheren Standpunkte aus. Teil 2. Geometrie, Teubner, Leipzig, (1909)

24. Locke, J.: An Essay Concerning Humane Understanding in Four books. Printed for Tho. Basset, and sold by Edw. Mory, London (1690)

25. Mancosu, P.: (ed. and trans.) From Brouwer to Hilbert: The Debate on the Foundations of Mathematics in the 1920s, Oxford, Oxford University Press (1998) 
26. Mathews, G.: Projective Geometry. Longmans. Green \& Co., New York (1914)

27. Newton, I.: Observations on Kinkhuysen's algebra (ca. 1670). Reprinted in Mathematical papers of Isaac Newton, volume II, 1667-1670, 364-444. D. T. Whiteside (ed.), Cambridge University Press (1968)

28. Reid, T.: Essays on the Intellectual Powers of Man. Printed for John Bell, and G. G. J. \& J. Robinson, London, 1785. Page references are to the 7 th ed., printed in (1872)

29. Resnik, M.: Frege and the Philosophy of Mathematics. Cornell U. Press (1980)

30. Shapiro, S.: Thinking about Mathematics: The Philosophy of Mathematics. Oxford University Press, Oxford (2000)

31. Smart, E.: A First Course in Projective Geometry. Macmillan \& Co., London (1913)

32. Thomae, J.: Elementare Theorie der analytischen Funktionen einer complexen Veränderlichen, 2nd edn. Nebert, Halle (1898)

33. van Heijenoort, J.: From Frege to Gödel: A Source Book in Mathematical Logic, 1879-1931. Harvard University Press, Cambridge (1967)

34. Weyl, H.: Diskussionsbemerkungen zu dem zweiten Hilbertschen Vortrag über die Grundlagen der Mathematik., Abhandlungen aus dem mathematischen Seminar der Hamburgischen Universität 6, 8688 (1928). Reprinted in Hamburger Einzelschriften 5, pp. 22-24, Teubner, Leipzig, 1928. English translation in [15] (1928)

35. Weyl, H.: Philosophie der Mathematik und Naturwissenschaft. R. Oldenblurg, Munich and Berlin (1928)

36. Weyl, H.: David Hilbert and his mathematical work. Bull. Am. Math. Soc. 50, 612-654 (1944)

37. Weyl, H.: Philosophy of Mathematics and Natural Science Princeton University Press, Princeton, 1949. English translation of the German original Philosophie der Mathematik und Naturwissenschaft, Oldenbourg, Munich and Berlin (1927)

38. Young, J.W., Denton, W.W., Mitchell, U.G.: Lectures on Fundamental Concepts of Algebra and Geometry. Macmillan Co., New York (1911)

39. Zermelo, E.: Untersuchungen über die Grundlagen der Mengenlehre I. Mathematische Annalen 65, 262-281 (1908)

Publisher's Note Springer Nature remains neutral with regard to jurisdictional claims in published maps and institutional affiliations. 